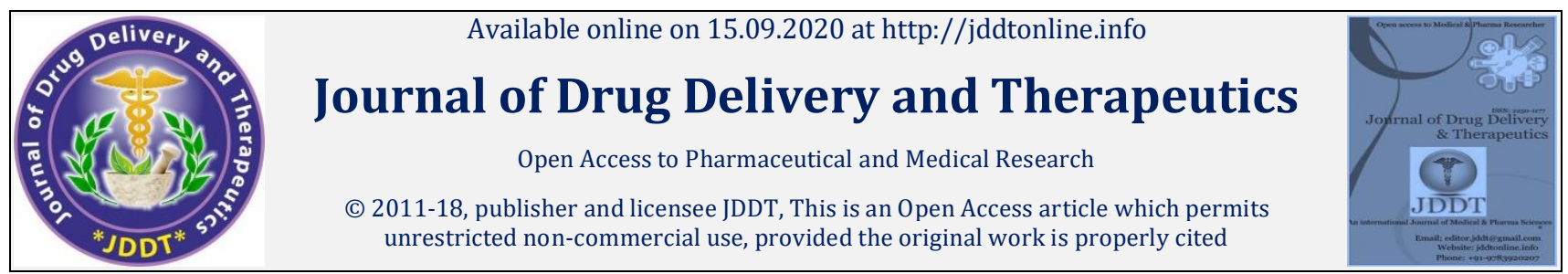

Open $\odot$ Access

Research Article

\title{
Synthesis and Pharmacological Evaluation of 2-(4-(3 (Substituted Phenyl) Acryloyl) Phenoxy)-N, N Diphenylacetamides
}

\author{
1,*Rohit Kumar, ${ }^{2}$ Sushil Kumar, ${ }^{3}$ Mohammad Asif Khan \\ ${ }^{1}$ Research Scholar, School of Pharmaceutical Sciences, IFTM University, Moradabad (UP) India \\ 2 Professor, School of Pharmaceutical Sciences, IFTM University, Moradabad (UP) India \\ ${ }^{3}$ Assistant Professor, Future Institute of Pharmacy, Future University, Bareilly (UP) India
}

\begin{abstract}
Recently a series of Schiff bases of diphenylamine derivatives have been synthesized and evaluated in vitro for their antibacterial activity against pathogenic both Gram-positive bacteria B. subtitles and Gram-negative bacteria E. coli using ciprofloxacin as standard drug at conc. of $50 \mu \mathrm{g} / \mathrm{ml}$ and $100 \mu \mathrm{g} / \mathrm{ml}$. Literature review revels that chalcones possesses various biological activities like antimicrobial, antiviral, antiinflammatory, anticancer and sedative etc. Therefore the present study was designed on synthesis and pharmacological evaluation of 2-(4-(3 (Substituted Phenyl) Acryloyl) Phenoxy)-N, N Diphenylacetamides. Target compound was synthesized by reaction of chloroacetylchloride with diphenylamine to afford 2-chloro-N, N-diphenylacetamide which further by reaction with substituted Chalcones and characterized following recrystallization and evaluated for anti-microbial potential through cup-diffusion method. In results, the target compounds were tested for activity against B. Subtilis, E.Coli and C. albicans. The chalcones having the lipophilic 4-chloro group (RKCT2) showed the greatest antimicrobial activity (zone of inhibition $20 \& 22 \mathrm{~mm}$ against. B. subtilis, E. Coli, C. Albicans respectively. It suggests further researchers to go through antimicrobial evaluations against a more varieties of bacteria and fungi.
\end{abstract}

Keywords: Schiff bases of diphenylamine derivatives, antibacterial activity, Gram-positive bacteria, 2-(4-(3 (Substituted Phenyl) Acryloyl) Phenoxy)-N, N Diphenylacetamides

Article Info: Received 17 July 2020; $\quad$ Review Completed 26 August 2020; Accepted 06 Sep 2020; Available online 15 Sep 2020

\section{Cite this article as:}

Kumar R, Kumar S, Khan MA, Synthesis and Pharmacological Evaluation of 2-(4-(3 (Substituted Phenyl) Acryloyl) Phenoxy)-N, N Diphenylacetamides, Journal of Drug Delivery and Therapeutics. 2020; 10(5):274-292 http://dx.doi.org/10.22270/jddt.v10i5.4326

*Address for Correspondence:

Mohammad Asif Khan, Assistant Professor, Future Institute of Pharmacy, Future University, Bareilly (UP) India

\section{INTRODUCTION}

Medicinal chemistry concerns the discovery, the development, the identification and the evaluation of the mode of action of biologically active compounds at the molecular extent [1]. A logical approach to the study of drugs and their activities is the recognition of the basic principles behind the biochemical events leading to drug action [2]. In recent years, medicinal chemistry has undergone a revolutionary change. Rapid advance in the biological sciences have resulted in a much better understanding of how the body functions at the cellular and molecular levels. Chalcones are natural compounds that are largely distributed in plants, fruits, and vegetables. The first aldol condensation product was reported by Kostanecki and he gave the name "Chalcones" or 1, 3-diaryl-2-propen-1-ones. They belong to the flavonoid group and act as precursors in the biosynthesis of anthocyanins and flavones [3].
A recent study has confirmed Green Expedient Synthesis of Pyrimidines Derivatives via Chalcones and Evaluation of their Anthelmintic Activity [4]. Green Synthesis of Chalcones as an Antioxidant and Anticancer was also determined [5]. Derivatives of Chalcones possess a broad spectrum of biological activity including ant oxidative, antibacterial, anthelmintic, amoebicidal, antiulcer, antiviral, insecticidal, antiprotozoal, anticancer, cytotoxicity and immunosuppressive [6] [7]

Recently a series of Schiff bases of diphenylamine derivatives have been synthesized and evaluated in vitro for their antibacterial activity against pathogenic both Gram-positive bacteria B. subtitles and Gram-negative bacteria E. coli using ciprofloxacin as standard drug at conc. of $50 \mu \mathrm{g} / \mathrm{ml}$ and 100 $\mu \mathrm{g} / \mathrm{ml}$. The compound displayed potent antibacterial activity against Bacillus subtitles (17 and $15 \mathrm{~mm}$ ) and Escherichia coli (19 and $17 \mathrm{~mm})$ by disc diffusion method [8]. 
Literature review revels that chalcones possesses various biological activities like antimicrobial, antiviral, antiinflammatory, anticancer and sedative etc.
Therefore the present study was designed on synthesis and pharmacological evaluation of 2-(4-(3 (Substituted Phenyl) Acryloyl) Phenoxy)-N, N Diphenylacetamides.<smiles>Cc1cccc(/N=C/c2ccc(OCC(=O)N(c3ccccc3)c3ccccc3)cc2)c1C</smiles>

\section{MATERIALS AND METHODS}

\section{Materials}

4-hydroxy acetophenone was purchased from Himedia. Diphenylamine, chloroacetylchloride, toluene, substituted benzaldehyde, base $(\mathrm{KOH})$ and all other chemicals and solvents were purchased from $\mathrm{CDH}$. All chemicals used were of analytical grades and purified before used.

\section{Methods}

\section{Synthesis and characterization of compounds}

\section{Step I: Synthesis of 2-Chloro-N, $\mathbf{N}$-diphenyl acetamides}

$6.76 \mathrm{~g}$ ( 0.04 mole) diphenylamine was dissolved in $50 \mathrm{ml}$ of toluene in a $100 \mathrm{ml}$ round bottom flask and $3.18 \mathrm{ml}(0.04$ mole) chloroacetylchloride was added. The reaction mixture was refluxed for $4 \mathrm{~h}$. After completion of reaction, the solution was cooled and poured in 100-200 ml of cold water and kept overnight for precipitation. The product was collected by vacuum filtration. The crude residue was recrystallized in ethanol.

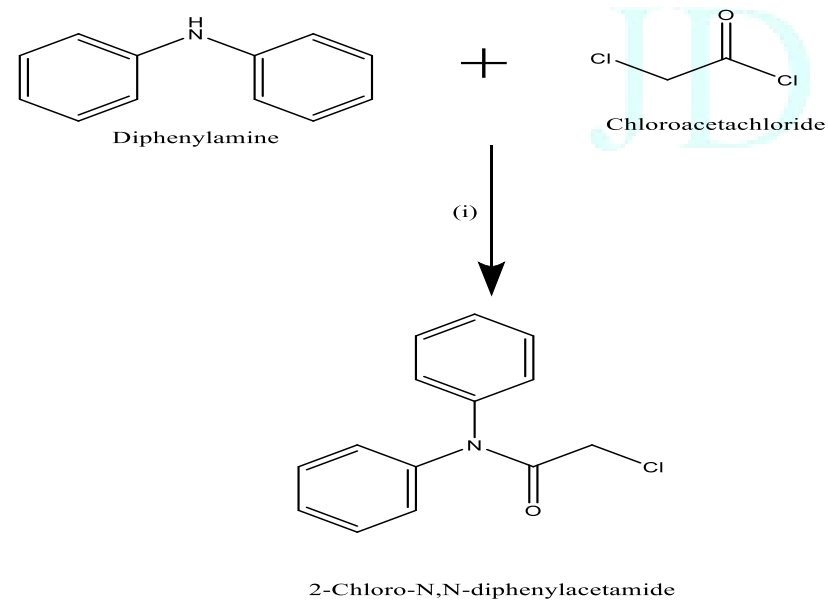

Scheme 1: Reagent and conditions: (i) Toluene, Reflux for 4 hr.

\section{Step II: Synthesis of Chalcones}

Equimolar amount of 4-hydroxyacetophenone and substituted benzaldehyde was dissolved in ethanol $(40 \mathrm{ml})$ and aqueous of potassium hydroxide $(40 \%, 15 \mathrm{ml})$ was added to it and stirred for $12 \mathrm{~h}$ at room temperature. The reaction mixture was kept overnight and then it was poured into crushed ice and acidified with dilute hydrochloric acid. The solid separated was filtered and dried to obtain the Chalcones (RKC1-10).

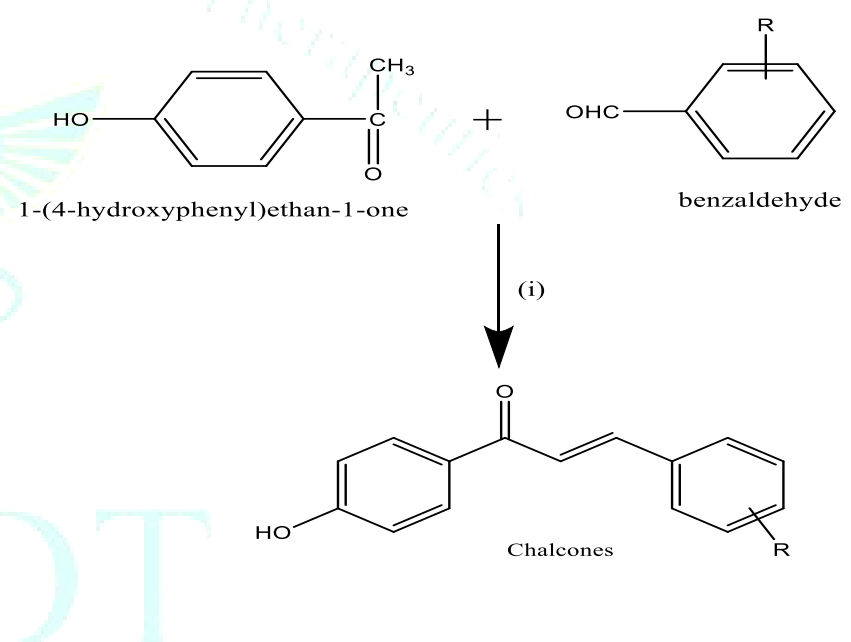

Scheme 1: Synthesis of Chalcones. Reagent and conditions: (I) Base, stir at room temp for $12 \mathrm{hrs}$.

\section{Step III: Synthesis of target compounds}

Equimolar mole of chalcone and 2-chloro-N, Ndiphenylacetamide was dissolved in $100 \mathrm{ml}$ of acetonitrile in a $250 \mathrm{ml}$ round bottom flask, double mole of anhydrous $\mathrm{K}_{2} \mathrm{CO}_{3}$, catalytic amount of potassium iodide were added into above solution. The above mixture was refluxed for $12 \mathrm{~h}$. After completion of reaction, the reaction mixture was filtered and solvent was removed under reduced pressure to obtain the crude product. The crude residue was washed with water and recrystallized from ethanol to afford the target compounds (RKCT1-10). 


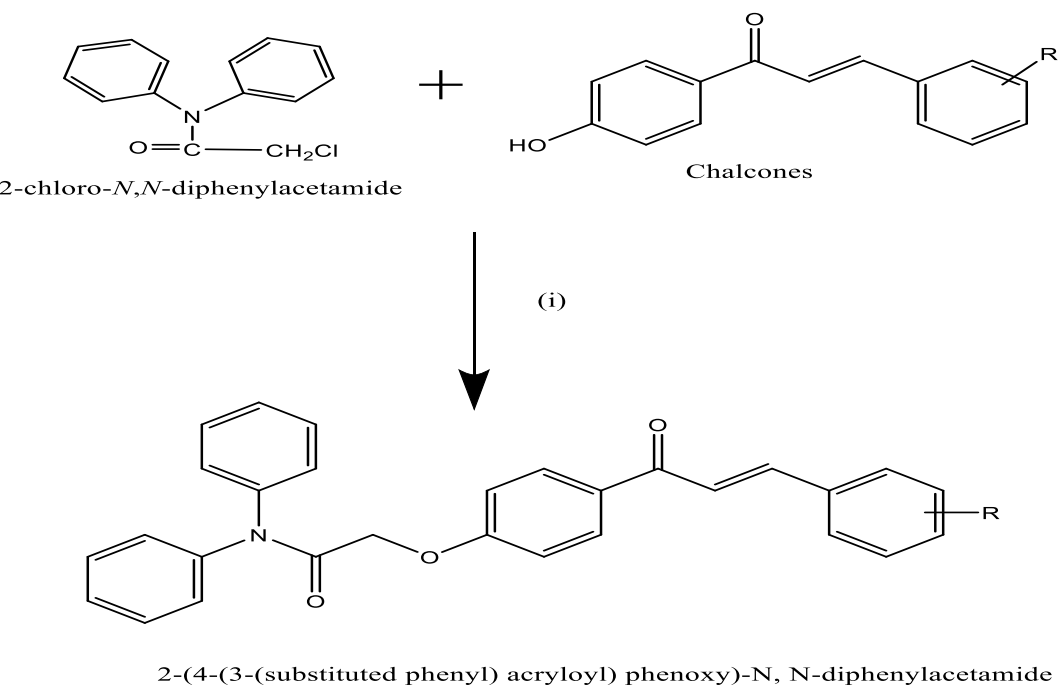

Scheme 1: Synthesis of target compounds. Reagent and conditions: (i) Acetonitrile, Anhydrous $\mathrm{K}_{2} \mathrm{CO}_{3}$, Reflux for12 hrs.

\section{Pharmacological Evaluation Method}

\section{Determination of Antimicrobial activity (Cup Diffusion technique)}

The antimicrobial testing was performed using the cup diffusion technique. The target compounds, as $1 \mathrm{mg} / \mathrm{ml}$ solutions in dimethylformamide (DMF), were evaluated in vitro for activity against $C$. albicans by the cup diffusion technique. Compounds showing inhibitory zones of at least $20 \mathrm{~mm}$ were considered active. Ampicillin and Clotrimazole were used as standard antimicrobial agents. Dimethylformamide was used as a control. Sterile nutrient agar was inoculated with the test organisms (each $100 \mathrm{~mL}$ of the medium received $1 \mathrm{~mL}$ of $24 \mathrm{~h}$ broth culture), and then seeded agar was poured into sterile petri dishes. Cups (8 $\mathrm{mm}$ in diameter) were cut in the agar, and each cup received $0.1 \mathrm{~mL}$ of the test compound solution. The plates were then incubated at $37^{\circ} \mathrm{C}$ for $24 \mathrm{~h}$. The activities were estimated as zones of inhibition in $\mathrm{mm}$ diameter (Table 4.22). Ampicillin and Clotrimazole solutions (0.01\%) were used as reference standards. DMF did not show any inhibition zones.

\section{RESULTS AND DISCUSSION}

\section{Step I: Synthesis of 2-Chloro-N, N-diphenyl acetamides}

The above synthesized compound shows following physical parameters-

\section{Physical parameters}

$\begin{array}{ll}\text { Practical yield } & 6.19 \mathrm{~g} \\ \text { Percentage yield } & 91.56 \% \\ \text { Melting range } & 115-117^{\circ} \mathrm{C} . \\ \text { Rf value } & 0.85 \\ \text { Mobile phase } & \mathrm{n} \text { - hexane: Ethyl acetate (1:1) } \\ \text { Molecular formula } & \mathrm{C}_{14} \mathrm{H}_{12} \mathrm{ClNO}\end{array}$

\section{Step II: Synthesis of Chalcones}

The above synthesized Chalcones compound shows following physical parameters-

Table 1. Physical parameters of synthesized Chalcones

\begin{tabular}{|c|c|c|c|c|}
\hline S.No & $\mathbf{R}$ & Cpd. Code & $\begin{array}{c}\mathbf{m . p .} \\
\left({ }^{\mathbf{0} C} \mathbf{2} \mathbf{2}\right)\end{array}$ & $\begin{array}{c}\mathbf{R}_{\mathbf{f}} \\
\text { (N-Hexane: Ethylacetate,1:1) }\end{array}$ \\
\hline 1 & H & RKC1 & 122 & 0.86 \\
\hline 2 & 4-Chloro & RKC2 & 135 & 0.75 \\
\hline 3 & 4- Bromo & RKC3 & 138 & 0.85 \\
\hline 4 & 3,4,5,Trimethoxy & RKC4 & 174 & 0.66 \\
\hline 5 & 3-Hydroxy & RKC5 & 179 & 0.82 \\
\hline 6 & 2-Methoxy & RKC6 & 136 & 0.61 \\
\hline 7 & 3-Nitro & RKC7 & 165 & 0.84 \\
\hline 8 & 4-Methyl & RKC8 & 121 & 0.66 \\
\hline 9 & 3,4-Dimethoxy & RKC9 & 144 & 0.71 \\
\hline 10 & 2-Chloro & RKC10 & 121 & \\
\hline
\end{tabular}




\section{Step III: Synthesis of target compounds}

The target synthesized compound shows following physical parameters-

Physical parameters

$\begin{array}{ll}\text { Practical yield } & 0.903 \mathrm{~g} \\ \text { Percentage yield } & 66.39 \% \\ \text { Melting range } & 90-93{ }^{\circ} \mathrm{C} . \\ \text { R } & 0.74 \\ \text { Mobalue } & \mathrm{n} \text { - hexane: Ethyl acetate (1:1) } \\ \text { Molecular formula } & \mathrm{C}_{29} \mathrm{H}_{23} \mathrm{NO}_{3}\end{array}$

IR, NMR Graphical observations of synthesized compounds

Structure of 2-(4-cinnamoylphenoxy)-N,N-diphenylacetamide (RKCT1)

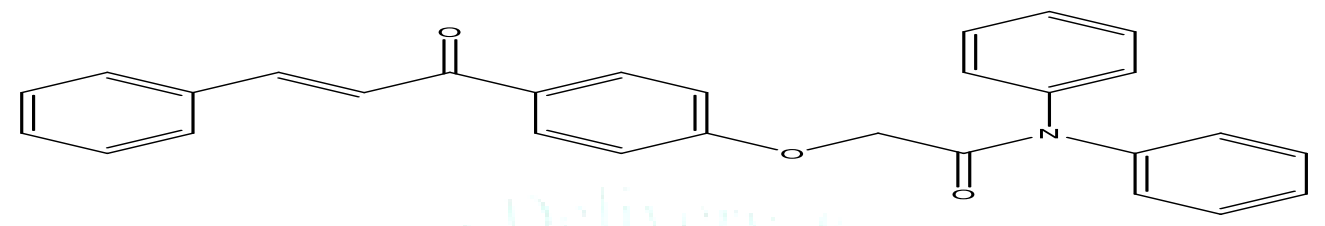

Graph 1. IR Spectrum of 2-(4-cinnamoylphenoxy)-N, N-diphenyl acetamide (RKCT1)

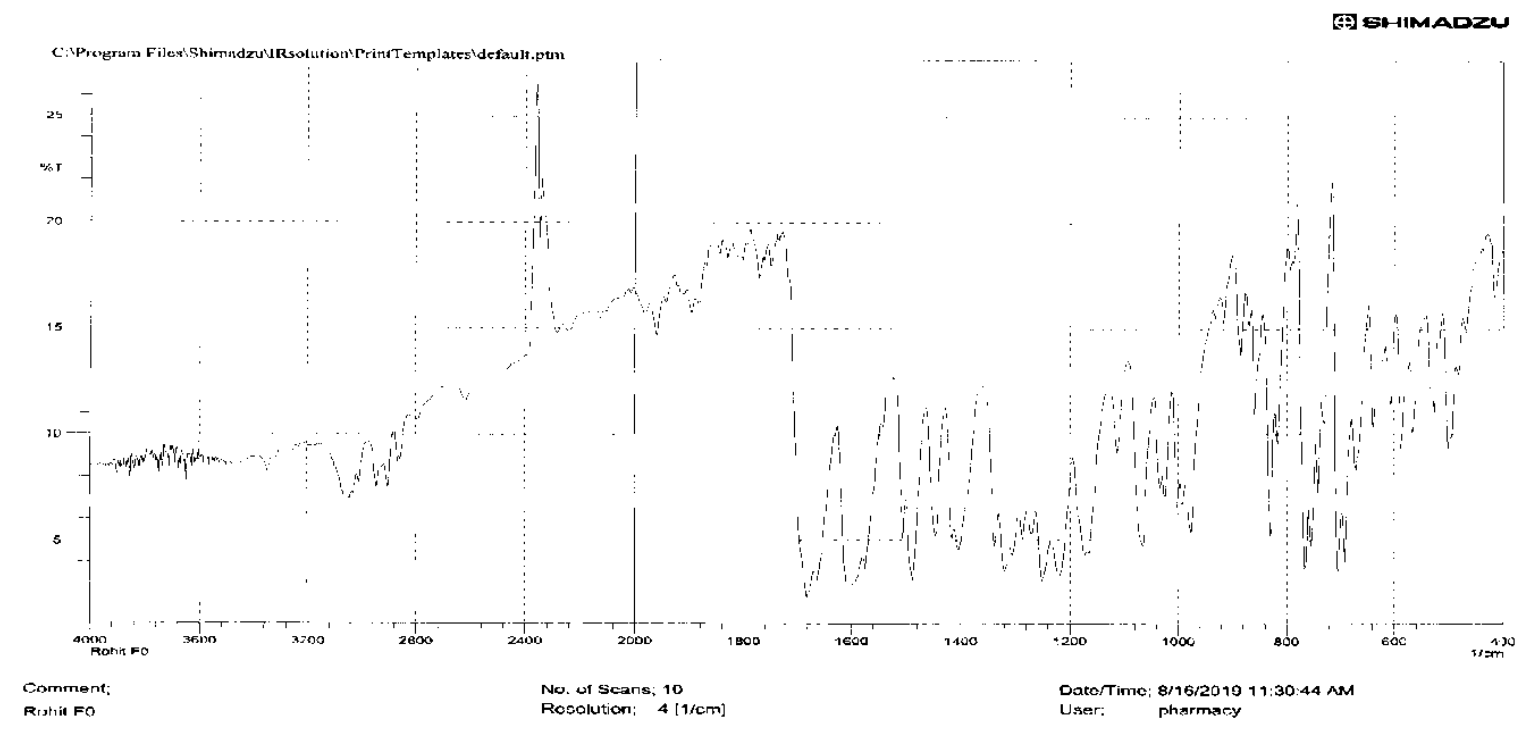

Table 2. IR spectrum data of 2-(4-cinnamoylphenoxy)-N, N-diphenyl acetamides (RKCT1)

\begin{tabular}{|c|c|c|}
\hline S.No. & Functional Group Assignment & $\mathbf{v ~ ( \mathbf { c m } ^ { - 1 } \mathbf { ) }}$ \\
\hline $\mathbf{1}$ & C-H str. Ar. & 3065 \\
\hline $\mathbf{2}$ & C-H str. Ali & 2910 \\
\hline $\mathbf{3}$ & C=O str. & 1680 \\
\hline $\mathbf{4}$ & C=C str. Ar. & 1510 \\
\hline $\mathbf{5}$ & C-N str. & 1260 \\
\hline $\mathbf{6}$ & C-O-C str. & 1110 \\
\hline
\end{tabular}


Graph 2. NMR spectrum of 2-(4-cinnamoylphenoxy)-N, N-diphenyl acetamide (RKCT1)

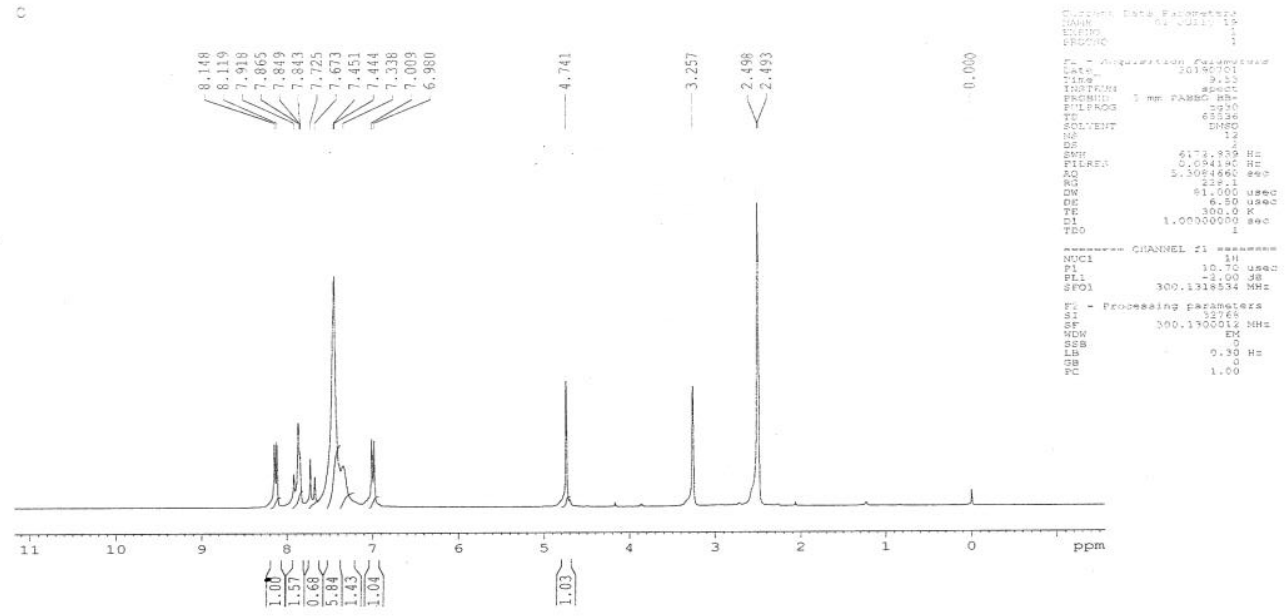

Table 3. NMR spectrum data of 2-(4-cinnamoylphenoxy)-N, N-diphenyl acetamide (RKCT1)

\begin{tabular}{|c|c|c|c|}
\hline S.No & Chemical shift( $)(\mathbf{p p m}$ & No. of Protons & Inferences \\
\hline $\mathbf{1}$ & $6.98-8.14$ & $19 \mathrm{H}-\mathrm{H}$ \\
\hline $\mathbf{2}$ & 4.74 & $2 \mathrm{H}$ & $-\mathrm{CH}_{2}$ \\
\hline $\mathbf{3}$ & 3.25 & $1 \mathrm{H}$ & $-\mathrm{CH}$ \\
\hline $\mathbf{4}$ & 2.49 & $1 \mathrm{H}$ & $-\mathrm{CH}$ \\
\hline
\end{tabular}

Structure of 2-(4-(3-(4-chlorophenyl) acryloyl) phenoxy)-N, N-diphenyl acetamide (RKCT2)<smiles>O=C(C=Cc1ccc(Cl)cc1)c1ccc(OCC(=O)N(c2ccccc2)c2ccccc2)cc1</smiles>

Physical parameters

$\begin{array}{ll}\text { Practical yield } & 0.98 \mathrm{~g} \\ \text { Percentage yield } & 73.68 \% \\ \text { Melting range } & 190-193{ }^{\circ} \mathrm{C} . \\ \text { Rf value } & 0.86 \\ \text { Mobile phase } & \text { n- hexane: Ethyl acetate }(1: 1) \\ \text { Molecular formula } & \mathrm{C}_{29} \mathrm{H}_{22} \mathrm{NClO}_{3}\end{array}$


Graph 3. IR spectrum of 2-(4-(3-(4-chlorophenyl) acryloyl) phenoxy)-N, N-diphenylacetamide (RKCT2)

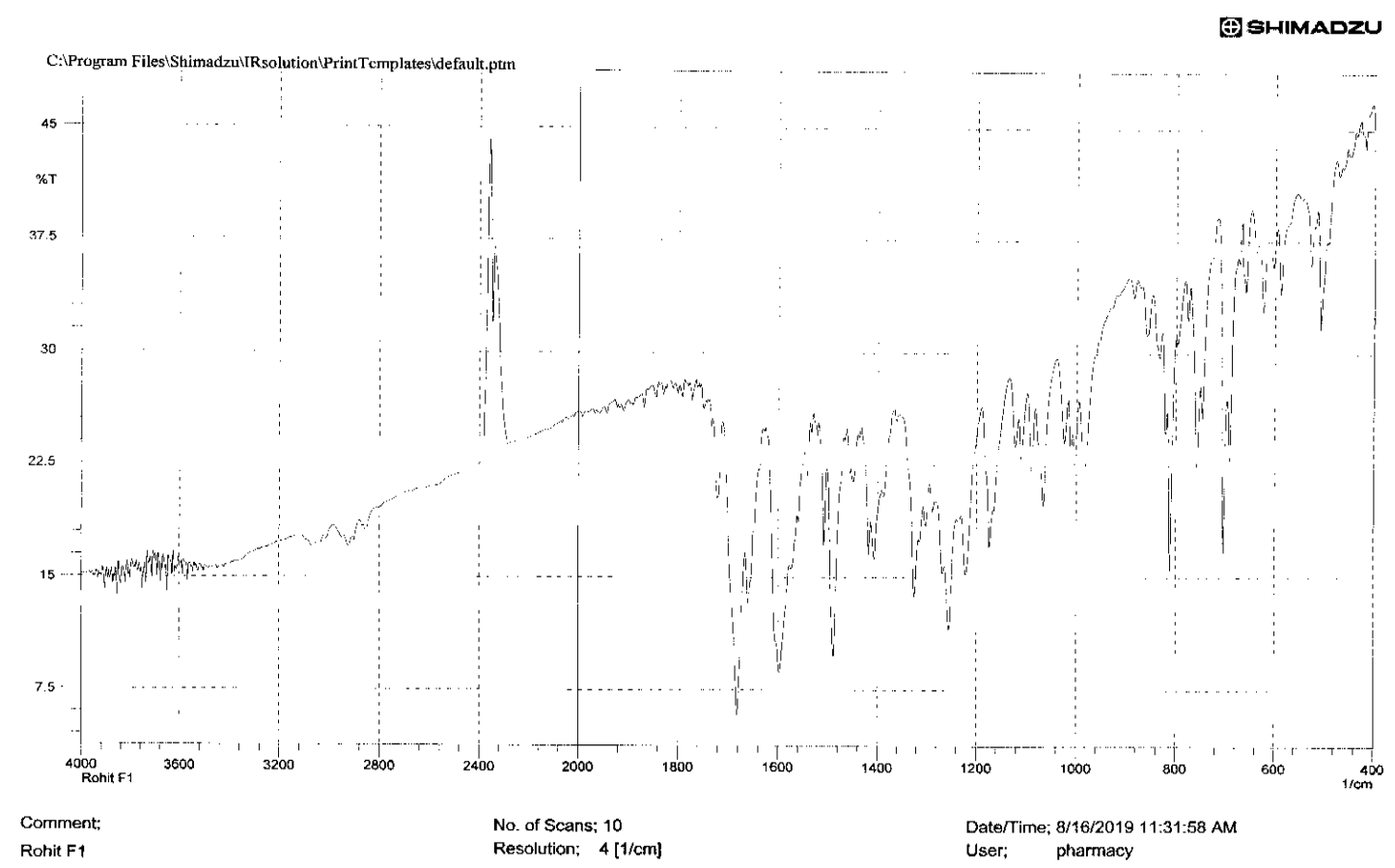

Table 4. IR spectrum data of (E)-2-(4-(3-(4-chlorophenyl) acryloyl) phenoxy)-N, N-diphenylacetamide (RKCT2)

\begin{tabular}{|c|c|c|}
\hline S.No. & Functional Group Assignment & $\mathbf{v ( \mathbf { c m } ^ { - 1 } )}$ \\
\hline 1 & C-H str. Ar. & 3080 \\
\hline 2 & C-H str. Ali & 2900 \\
\hline 3 & C=O str. & 1740 \\
\hline 4 & C=C str. Ar. & 1680 \\
\hline 5 & C-N str. & 1220 \\
\hline 6 & C-O-C str. & 1120 \\
\hline 7 & C-Cl str. & 760 \\
\hline
\end{tabular}

Graph 4. NMR spectrum of 2-(4-(3-(4-chlorophenyl) acryloyl) phenoxy)-N, N-diphenylacetamide (RKCT2)

1

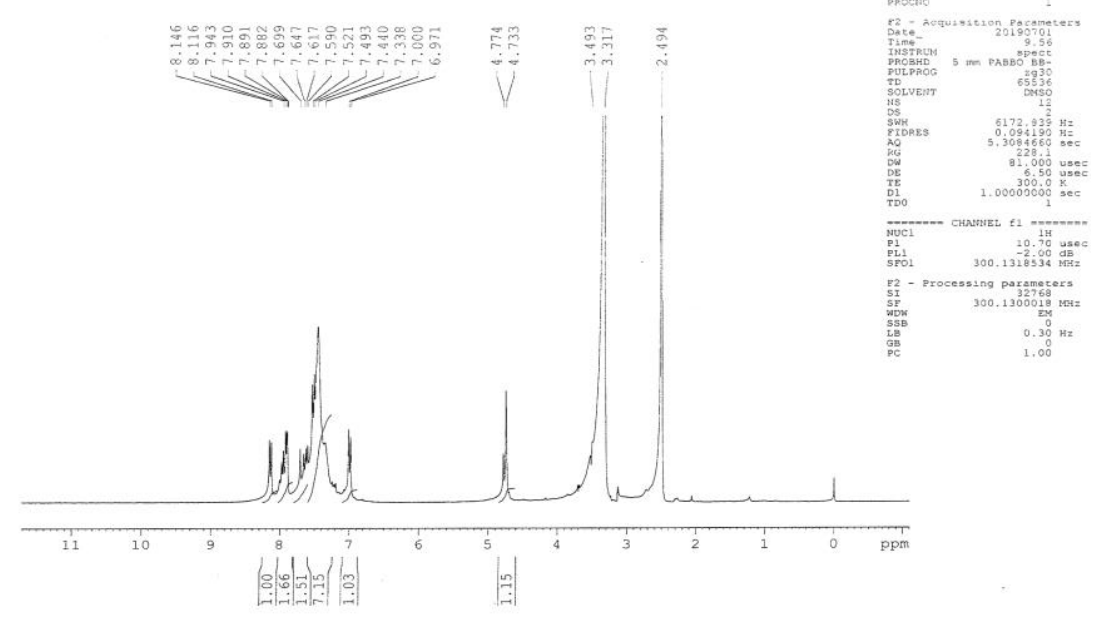


Table 5. NMR spectrum data of 2-(4-(3-(4-chlorophenyl) acryloyl) phenoxy)-N, N-diphenyl acetamide (RKCT2)

\begin{tabular}{|c|c|c|c|}
\hline S.No & Chemical shift( $\boldsymbol{\delta}$ (ppm & No. of Protons & Inferences \\
\hline $\mathbf{1}$ & $6.97-8.14$ & $18 \mathrm{H}-\mathrm{H}$ \\
\hline $\mathbf{2}$ & 4.77 & $2 \mathrm{H}$ & $-\mathrm{CH}_{2}$ \\
\hline $\mathbf{3}$ & 3.49 & $1 \mathrm{H}$ & $-\mathrm{CH}$ \\
\hline $\mathbf{4}$ & 2.49 & $1 \mathrm{H}$ & $-\mathrm{CH}$ \\
\hline
\end{tabular}

Structure of 2-(4-(3-(4-bromophenyl) acryloyl) phenoxy)-N, N-diphenylacetamide (RKCT3)<smiles>O=C(/C=C/c1ccc(Br)cc1)c1ccc(OCC(=O)N(c2ccccc2)c2ccccc2)cc1</smiles>

Physical parameters:

$$
\begin{array}{ll}
\text { Practical yield } & 0.891 \mathrm{~g} \\
\text { Percentage yield } & 68.52 \% \\
\text { Melting range } & 132-135{ }^{\circ} \mathrm{C} . \\
\text { R } & 0.74 \\
\text { Mobilue } & \mathrm{n} \text { - hexane: Ethyl acetate }(1: 1) \\
\text { Molecular formula } & \mathrm{C}_{29} \mathrm{H}_{22} \mathrm{NBrO}_{3}
\end{array}
$$

Graph 5. IR spectrum of 2-(4-(3-(4-bromophenyl) acryloyl) phenoxy)-N, N-diphenylacetamide (RKCT3)

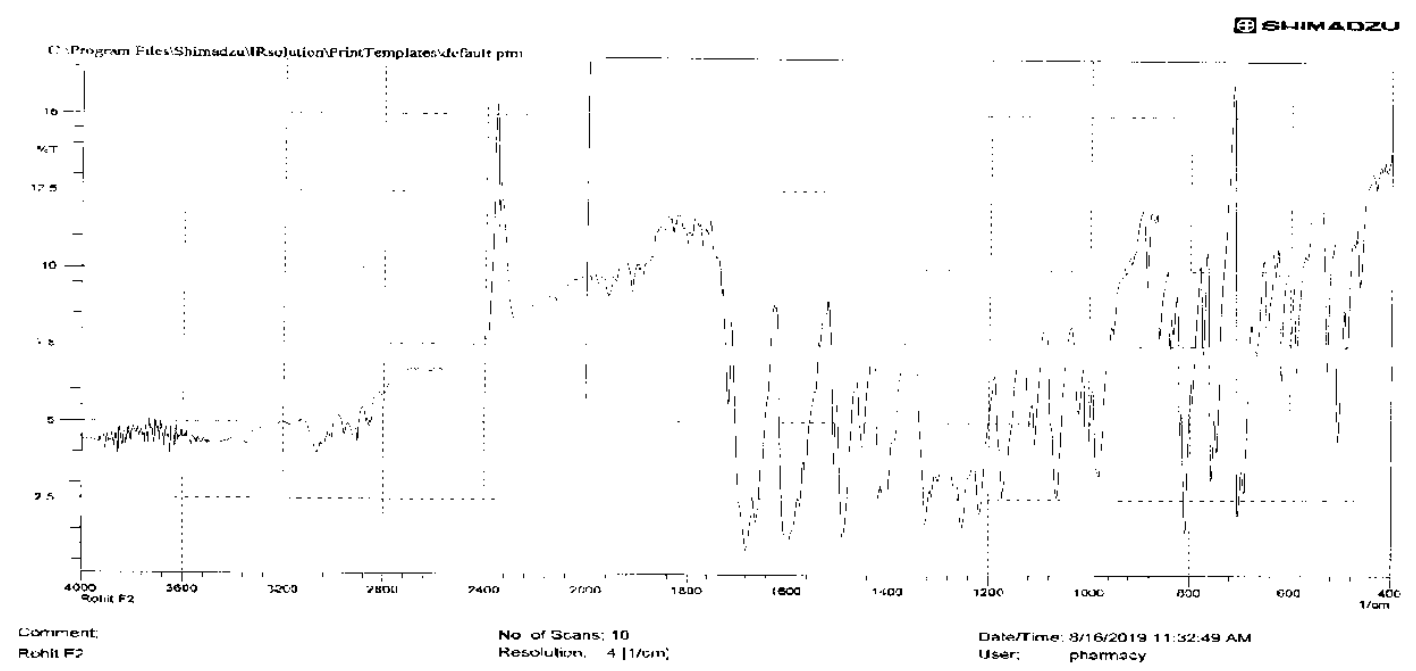

Table 6. IR spectrum data of 2-(4-(3-(4-bromophenyl) acryloyl) phenoxy) -N, N- diphenylacetamide (RKCT3)

\begin{tabular}{|c|c|c|}
\hline S.No. & Functional Group Assignment & $\mathbf{v}\left(\mathbf{c m}^{-1}\right)$ \\
\hline $\mathbf{1}$ & C-H str. Ar. & 3070 \\
\hline $\mathbf{2}$ & C-H str. Ali & 2900 \\
\hline $\mathbf{3}$ & C=O str. & 1720 \\
\hline $\mathbf{4}$ & C=C str. Ar. & 1680 \\
\hline $\mathbf{5}$ & C-N str. & 1220 \\
\hline $\mathbf{6}$ & C-O-C str. & 1110 \\
\hline $\mathbf{7}$ & C-Br str. & 590 \\
\hline
\end{tabular}


Graph 6. NMR spectrum of 2-(4-(3-(4-bromophenyl) acryloyl) phenoxy) -N, N-diphenylacetamide (RKCT3)

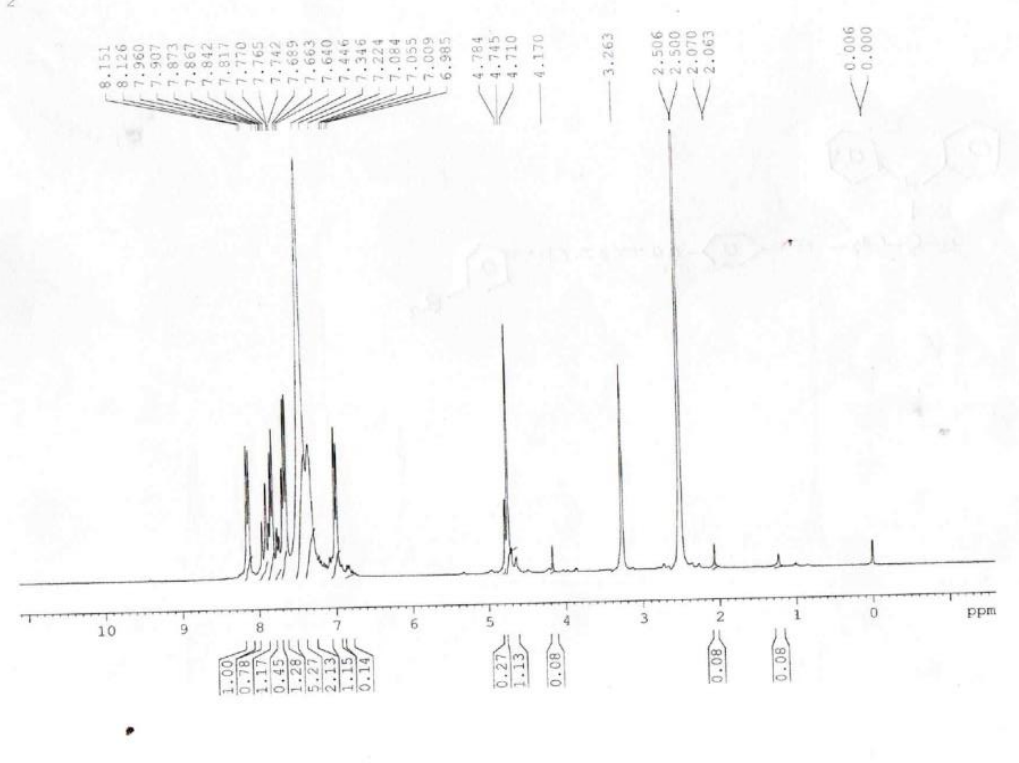

Table 7. NMR spectrum data of 2-(4-(3-(4-bromophenyl) acryloyl) phenoxy) -N, N-diphenylacetamide (RKCT3)

\begin{tabular}{|c|c|c|c|}
\hline S.No & Chemical shift( $\boldsymbol{\delta})(\mathbf{p p m}$ & No. of Protons & Inferences \\
\hline $\mathbf{1}$ & $6.98-8.15$ & $18 \mathrm{H}$ & $\mathrm{Ar}-\mathrm{H}$ \\
\hline $\mathbf{2}$ & 4.78 & $2 \mathrm{H}$ & $-\mathrm{CH}_{2}$ \\
\hline $\mathbf{3}$ & 2.50 & $2 \mathrm{H}$ & $-\mathrm{CH}$ \\
\hline
\end{tabular}

Structure of 2-(4-(3-(3,4,5 trimethoxyphenyl) acryloyl) phenoxy) -N, N-diphenyl acetamide (RKCT4)<smiles>COc1cc(/C=C/C(=O)c2ccc(OCC(=O)N(c3ccccc3)c3ccccc3)cc2)cc(OC)c1OC</smiles>

4.2.3.1. Physical parameters:

$\begin{array}{ll}\text { Practical yield } & 1.01 \mathrm{~g} \\ \text { Percentage yield } & 84.87 \% \\ \text { Melting range } & 139-142^{\circ} \mathrm{C} \\ \mathrm{R}_{\mathrm{f}} \text { value } & 0.43 \\ \text { Mobile phase } & \mathrm{n} \text { - hexane: Ethyl acetate }(1: 1) \\ \text { Molecular formula } & \mathrm{C}_{32} \mathrm{H}_{29} \mathrm{NO}_{6}\end{array}$


Graph 7. IR spectrum of 2-(4-(3-(3, 4, 5 trimethoxy phenyl) acryloyl) phenoxy)-N, N-diphenylacetamide (RKCT4)

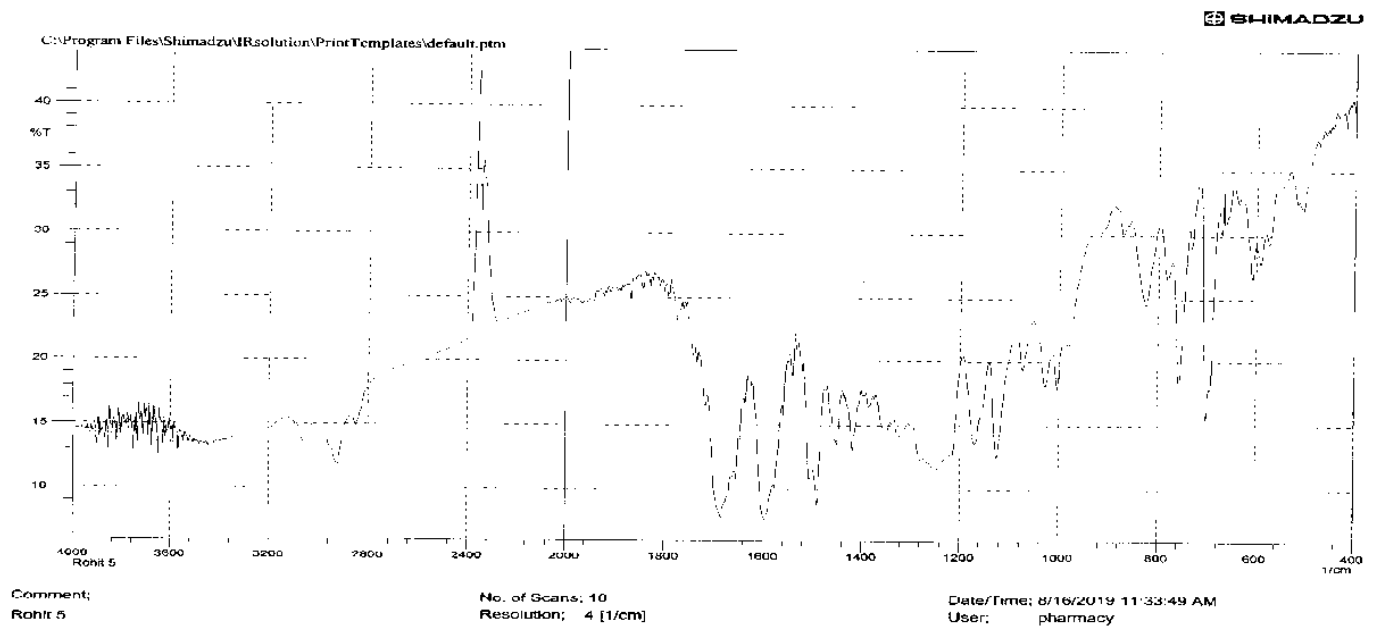

Table 8. IR spectrum data of 2-(4-(3-(3,4,5 trimethoxy phenyl) acryloyl) phenoxy) -N, N-diphenylacetamide (RKCT4)

\begin{tabular}{|c|c|c|}
\hline S.No. & Functional Group Assignment & $\mathbf{v ~ ( \mathbf { c m } ^ { - 1 } )}$ \\
\hline $\mathbf{1}$ & C-H str. Ar. & 3070 \\
\hline $\mathbf{2}$ & C-H str. Ali & 2900 \\
\hline $\mathbf{3}$ & C=O str. & 1720 \\
\hline $\mathbf{4}$ & C=C str. Ar. & 1655 \\
\hline $\mathbf{5}$ & C-N str. & 1130 \\
\hline $\mathbf{6}$ & C-O-C str. & 1150 \\
\hline
\end{tabular}

Graph 8. NMR spectrum of 2-(4-(3-(3, 4, 5 trimethoxy phenyl) acryloyl) phenoxy)-N, N-diphenylacetamide (RKCT4)

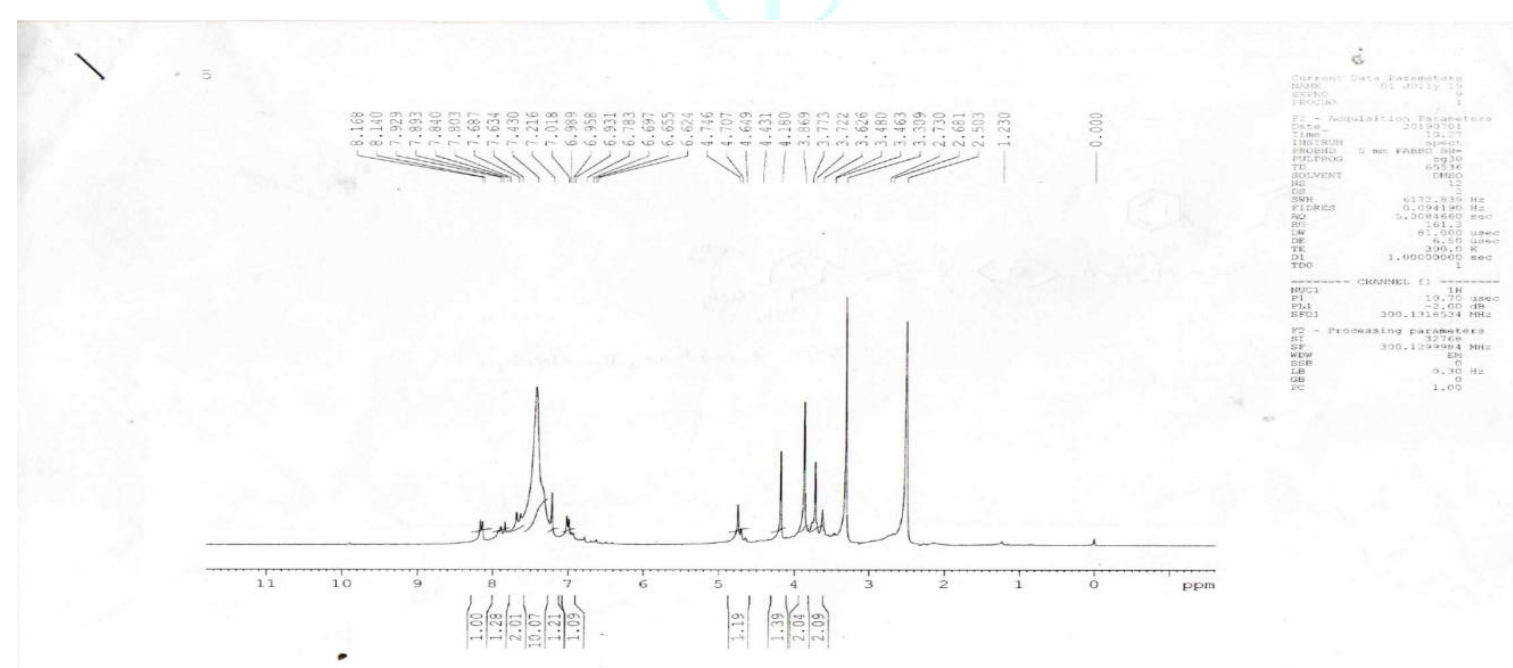

Table 9. NMR spectrum data of 2-(4-(3-(3, 4, 5 trimethoxyphenyl) acryloyl) phenoxy)-N, N-diphenylacetamide (RKCT4)

\begin{tabular}{|c|c|c|c|}
\hline S.No & Chemical shift( $)(\mathbf{p p m}$ & No. of Protons & Inferences \\
\hline $\mathbf{1}$ & $6.62-8.16$ & $16 \mathrm{H}-\mathrm{H}$ \\
\hline $\mathbf{2}$ & 4.74 & $2 \mathrm{H}$ & $-\mathrm{CH}_{2}$ \\
\hline $\mathbf{3}$ & 3.86 & $3 \mathrm{H}$ & $-\mathrm{OCH}_{3}$ \\
\hline $\mathbf{4}$ & 3.72 & $3 \mathrm{H}$ & $-\mathrm{OCH}_{3}$ \\
\hline $\mathbf{5}$ & 3.62 & $3 \mathrm{H}$ & $-\mathrm{OCH}_{3}$ \\
\hline $\mathbf{6}$ & 2.50 & $2 \mathrm{H}$ & $-\mathrm{CH}$ \\
\hline
\end{tabular}


Structure of 2-(4-(3-(3-hydroxyphenyl) acryloyl) phenoxy)-N, N-diphenylacetamide (RKCT5)<smiles>O=C(/C=C/c1cccc(O)c1)c1ccc(OCC(=O)N(c2ccccc2)c2ccccc2)cc1</smiles>

\section{Physical parameters:}

$\begin{array}{ll}\text { Practical yield } & 1.02 \mathrm{~g} \\ \text { Percentage yield } & 72.34 \% \\ \text { Melting range } & 120-123^{\circ} \mathrm{C} \\ \text { Rf value } & 0.71 \\ \text { Mobile phase } & n-h e x a n e: \text { Ethyl acetate }(1: 1) \\ \text { Molecular formula } & \mathrm{C}_{29} \mathrm{H}_{23} \mathrm{NO}_{4}\end{array}$

Graph 9. IR spectrum of 2-(4-(3-(3-hydroxyphenyl) acryloyl) phenoxy)-N, N-diphenylacetamide (RKCT5)

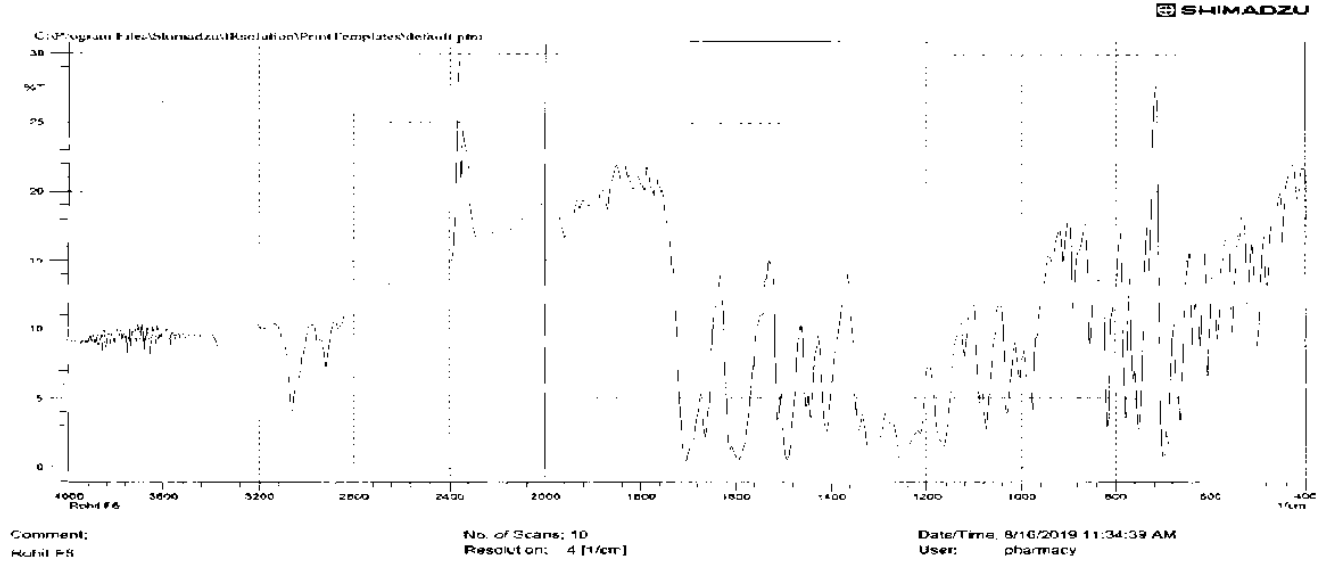

Table 10. IR spectrum data of 2-(4-(3-(3-hydroxyphenyl) acryloyl) phenoxy)-N, N-diphenylacetamide (RKCT5)

\begin{tabular}{|c|c|c|}
\hline S.No. & Functional Group Assignment & $\mathbf{v ( \mathbf { c m } ^ { - 1 } )}$ \\
\hline $\mathbf{1}$ & C-H str. Ar. & 3065 \\
\hline $\mathbf{2}$ & C-H str. Ali & 2900 \\
\hline $\mathbf{3}$ & C=O str. & 1710 \\
\hline $\mathbf{4}$ & C=C str. Ar. & 1660 \\
\hline $\mathbf{5}$ & C-N str. & 1170 \\
\hline $\mathbf{6}$ & C-O-C str. & 1010 \\
\hline $\mathbf{7}$ & O-H str. & 3650 \\
\hline
\end{tabular}


Graph 10. NMR spectrum of 2-(4-(3-(3-hydroxyphenyl)acryloyl) phenoxy) -N,N-diphenylacetamide (RKCT5)

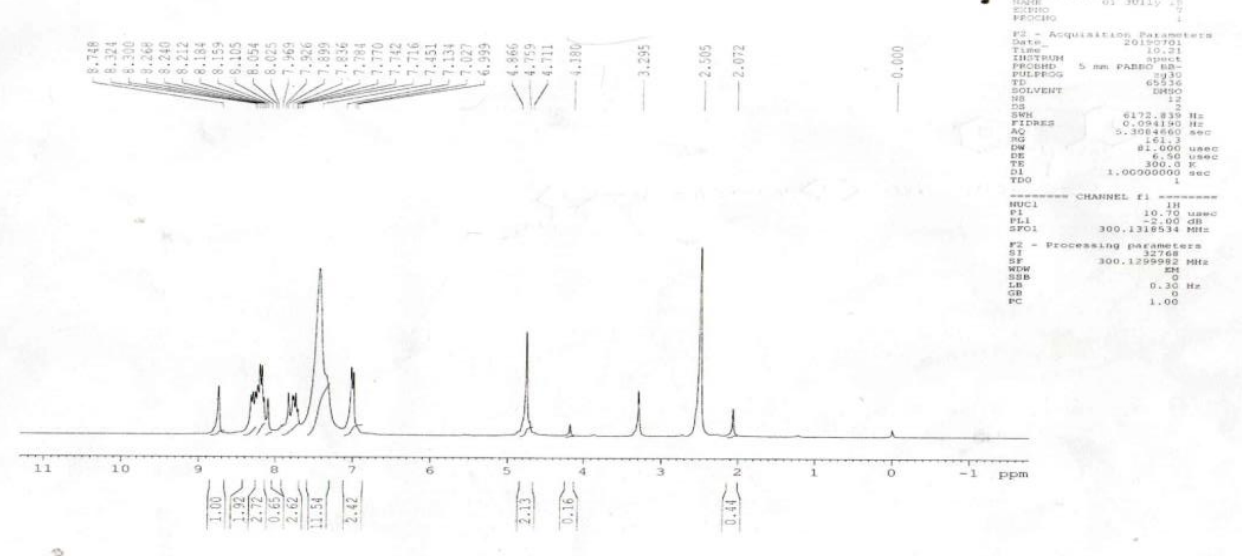

Table 11. NMR spectrum data of 2-(4-(3-(3-hydroxyphenyl) acryloyl) phenoxy)-N, N-diphenylacetamide (RKCT5)

\begin{tabular}{|c|c|c|c|}
\hline S.No & Chemical shift( $\boldsymbol{\delta})(\mathbf{p p m}$ & No. of Protons & Inferences \\
\hline $\mathbf{1}$ & $6.90-8.15$ & $18 \mathrm{H}$ & $\mathrm{Ar}-\mathrm{H}$ \\
\hline $\mathbf{2}$ & 4.74 & $2 \mathrm{H}$ & $-\mathrm{CH}_{2}$ \\
\hline $\mathbf{3}$ & 3.31 & $1 \mathrm{H}$ & $-\mathrm{CH}$ \\
\hline $\mathbf{4}$ & 2.50 & $1 \mathrm{H}$ & $-\mathrm{CH}$ \\
\hline $\mathbf{5}$ & 1.23 & $1 \mathrm{H}$ & $-\mathrm{OH}$ \\
\hline
\end{tabular}

2-(4-(3-(2-methoxyphenyl)acryloyl)phenoxy)-N,N-diphenylacetamide (RKCT6).<smiles>COc1ccccc1/C=C/C(=O)c1ccc(OCC(=O)N(c2ccccc2)c2ccccc2)cc1</smiles>

Physical parameters

Practical yield
Percentage yield
Melting range
Rf value $^{\text {f }}$

Mobile phase

Molecular formula
$1.58 \mathrm{~g}$

$68.22 \%$

$140-143^{\circ} \mathrm{C}$

0.71

n- hexane: Ethyl acetate (1:1)

$\mathrm{C}_{30} \mathrm{H}_{25} \mathrm{NO}_{4}$

Graph 11. IR spectrum of 2-(4-(3-(2-methoxyphenyl) acryloyl) phenoxy)-N, N-diphenylacetamide (RKCT6)
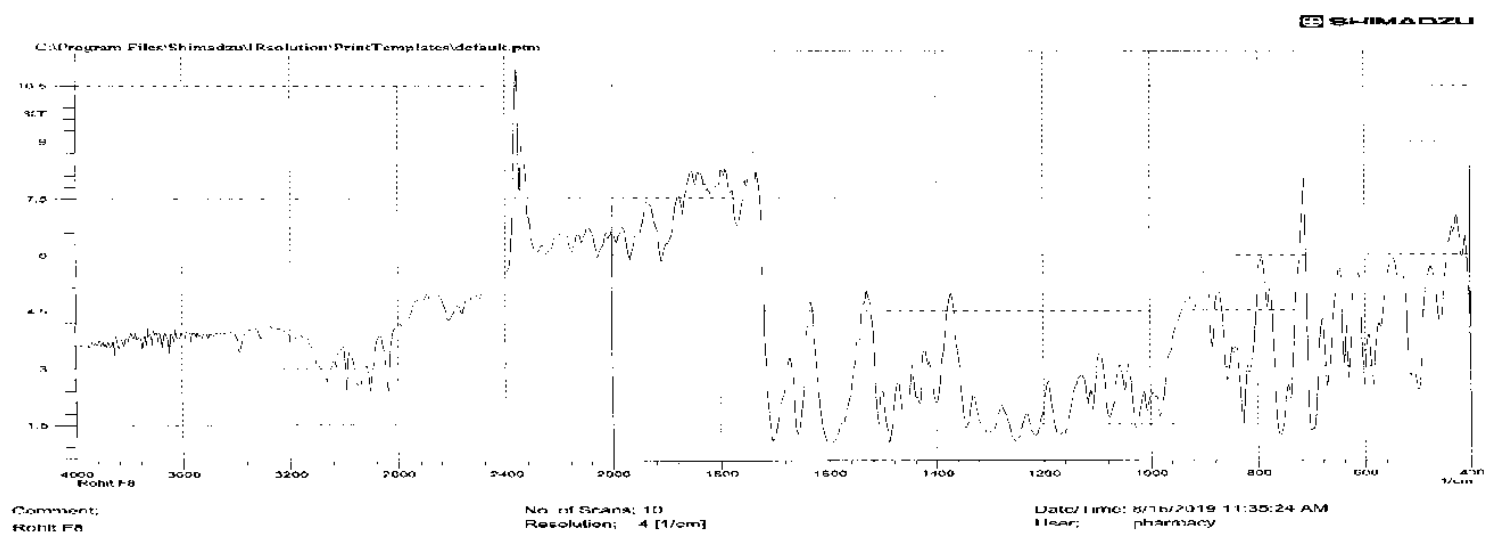
Table 12. IR spectrum data of 2-(4-(3-(2-methoxyphenyl) acryloyl) phenoxy) -N, N-diphenylacetamide (RKCT6)

\begin{tabular}{|c|c|c|}
\hline S.No. & Functional Group Assignment & $\mathbf{v}\left(\mathbf{c m}^{-1}\right)$ \\
\hline $\mathbf{1}$ & C-H str. Ar. & 2960 \\
\hline $\mathbf{2}$ & C-H str. Ali & 2910 \\
\hline $\mathbf{3}$ & C=O str. & 1710 \\
\hline $\mathbf{4}$ & C=C str. Ar. & 1160 \\
\hline $\mathbf{5}$ & C-N str. & 1170 \\
\hline $\mathbf{6}$ & C-O-C str. & 1110 \\
\hline
\end{tabular}

Graph 12. NMR spectrum of 2-(4-(3-(2-methoxyphenyl) acryloyl) phenoxy)-N, N-diphenylacetamide (RKCT6)

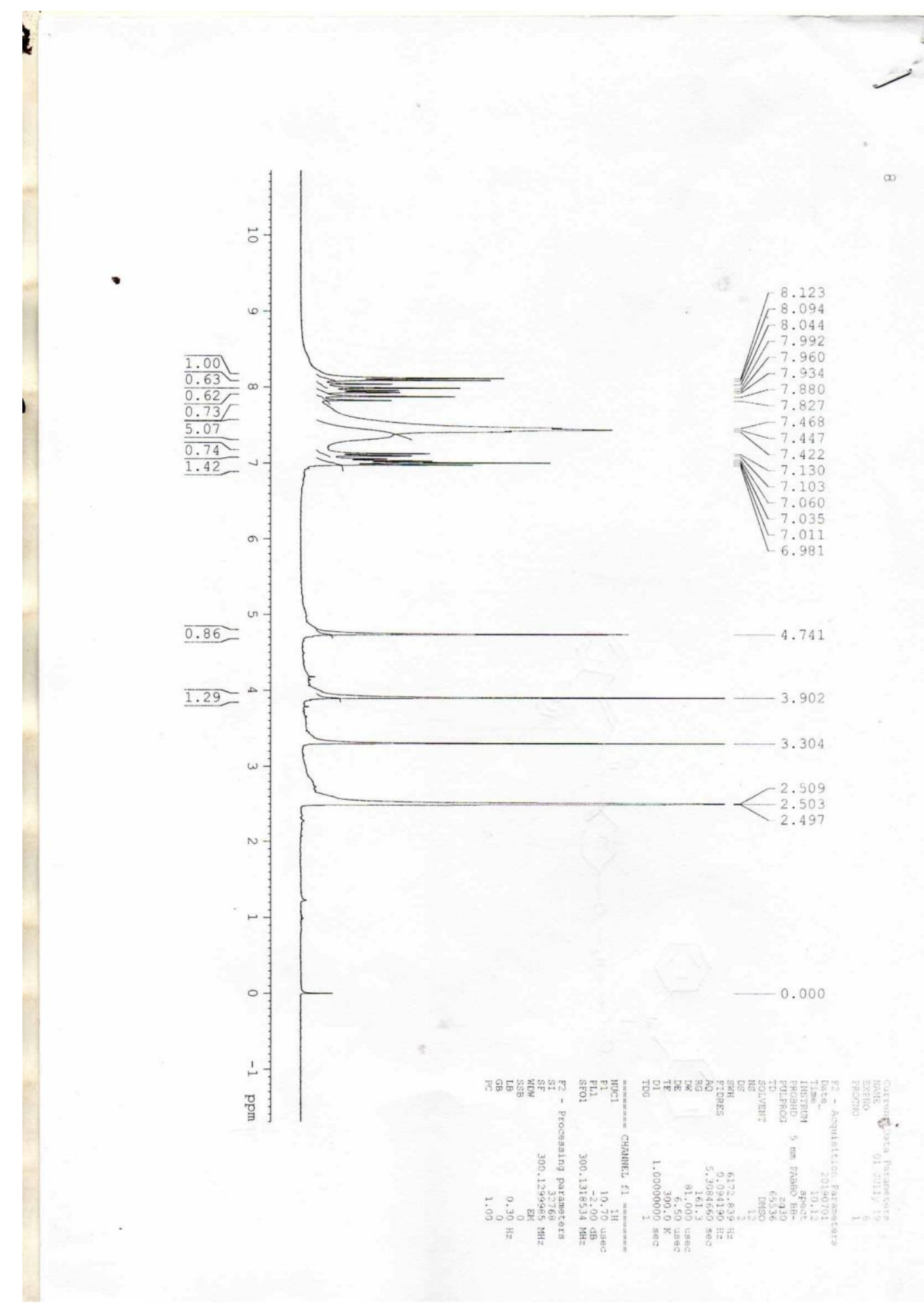


Table 13. NMR spectrum data of 2-(4-(3-(2-methoxyphenyl ) acryloyl) phenoxy)-N,N-diphenylacetamide (RKCT6)

\begin{tabular}{|c|c|c|c|}
\hline S.No & Chemical shift( $)(\mathbf{p p m}$ & No. of Protons & Inferences \\
\hline 1 & $6.98-8.12$ & $18 \mathrm{H}-\mathrm{H}$ \\
\hline 2 & 4.74 & $2 \mathrm{H}$ & $-\mathrm{CH}_{2}$ \\
\hline 3 & 3.90 & $3 \mathrm{H}$ & $-\mathrm{OCH}_{3}$ \\
\hline 4 & 2.50 & $2 \mathrm{H}$ & $-\mathrm{CH}$ \\
\hline
\end{tabular}

Structure of 2-(4-(3-(3-nitrophenyl)acryloyl)phenoxy)-N,N-diphenyl acetamide(RKCT7)<smiles>O=C(/C=C/c1cccc([N+](=O)[O-])c1)c1ccc(OCC(=O)N(c2ccccc2)c2ccccc2)cc1</smiles>

Physical parameters

$\begin{array}{ll}\text { Practical yield } & 1.02 \mathrm{~g} \\ \text { Percentage yield } & 76.11 \% \\ \text { Melting range } & 145-148{ }^{\circ} \mathrm{C} \\ \text { Rf value } & 0.74 \\ \text { Mobile phase } & \text { n- hexane: Ethyl acetate (1:1) } \\ \text { Molecular formula } & \mathrm{C}_{29} \mathrm{H}_{22} \mathrm{~N}_{2} \mathrm{O}_{5}\end{array}$

Graph 13. IR spectrum of 2-(4-(3-(3-nitrophenyl) acryloyl) phenoxy)-N, N-diphenylacetamide (RKCT7)

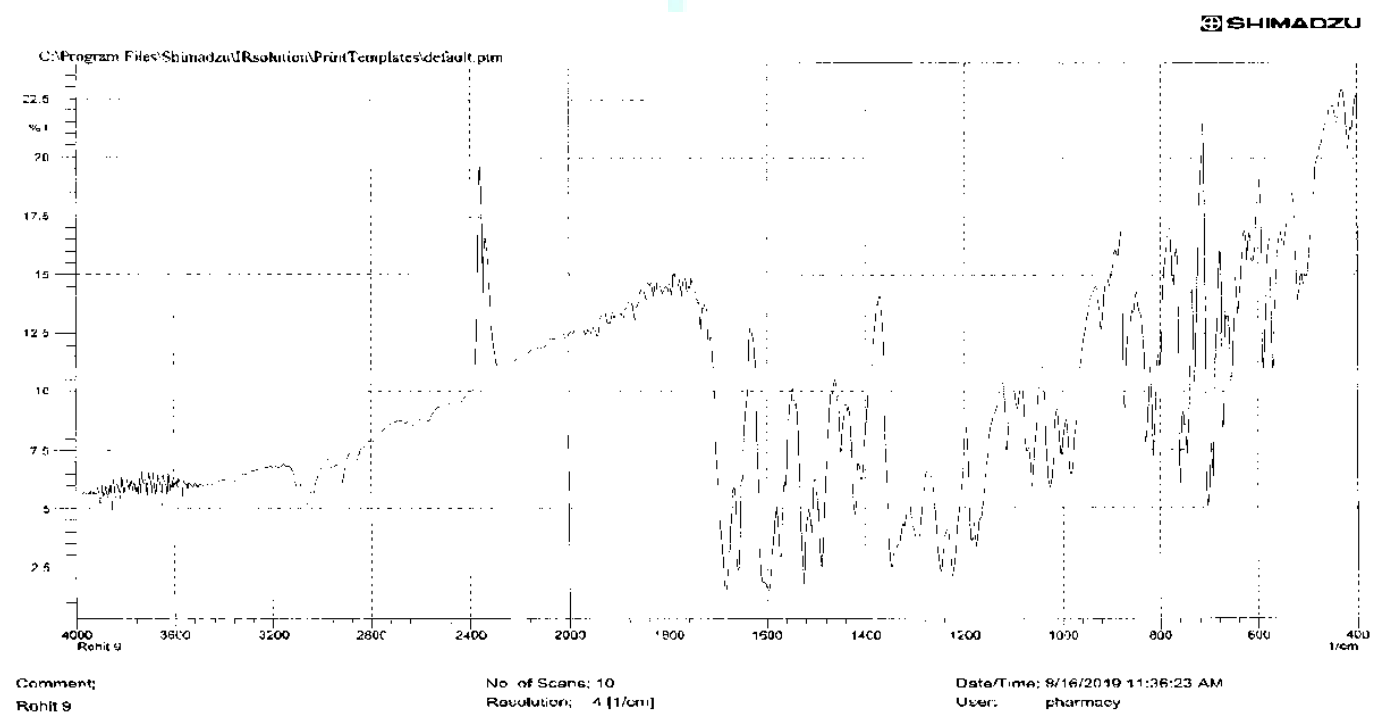

Table 14. IR spectrum data of 2-(4-(3-(3-nitrophenyl)acryloyl) phenoxy) -N,N-diphenylacetamide (RKCT7)

\begin{tabular}{|c|c|c|}
\hline S.No. & Functional Group Assignment & $\mathbf{v}\left(\mathbf{c m}^{-1} \mathbf{)}\right.$ \\
\hline $\mathbf{1}$ & C-H str. Ar. & 3060 \\
\hline $\mathbf{2}$ & C-H str. Ali & 2920 \\
\hline $\mathbf{3}$ & C=O str. & 1719 \\
\hline $\mathbf{4}$ & C=C str. Ar. & 1660 \\
\hline $\mathbf{5}$ & C-N str. & 1230 \\
\hline $\mathbf{6}$ & C-O-C str. & 1115 \\
\hline $\mathbf{7}$ & N-O str. & 1290 \\
\hline
\end{tabular}


Graph 14. NMR spectrum of 2-(4-(3-(3-nitrophenyl)acryloyl)phenoxy)-N,N-diphenylacetamides (RKCT7)

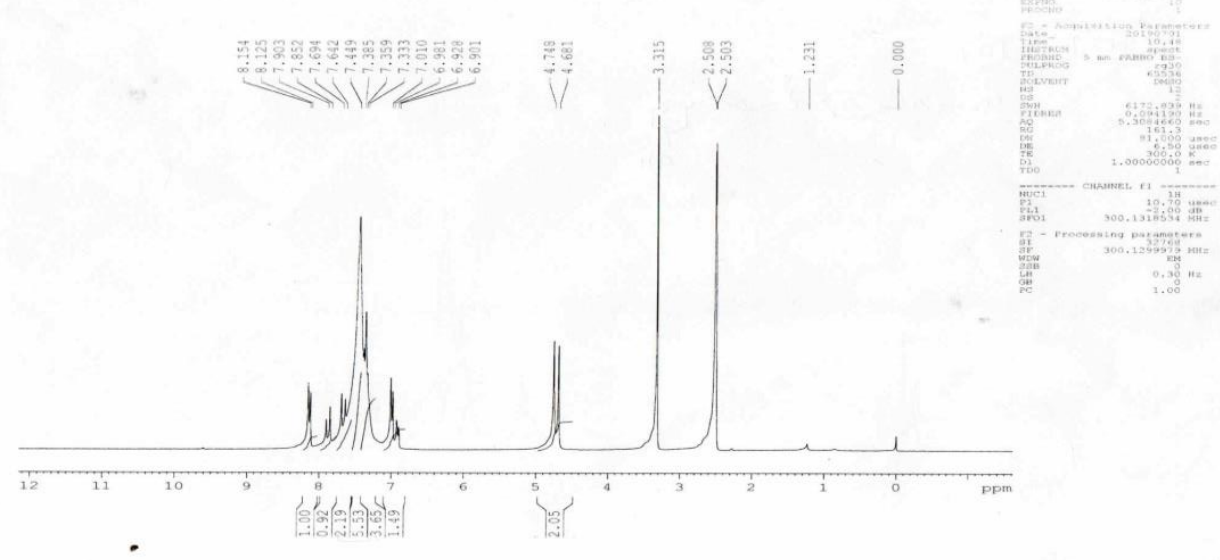

Table 15. NMR spectrum data of 2-(4-(3-(3-nitrophenyl)acryloyl) phenoxy) -N,N-diphenylacetamide(RKCT7)

\begin{tabular}{|c|c|c|c|}
\hline S.No & Chemical shift( $\boldsymbol{\delta})(\mathbf{p p m}$ & No. of Protons & Inferences \\
\hline $\mathbf{1}$ & $6.99-8.74$ & $18 \mathrm{H}-\mathrm{H}$ \\
\hline $\mathbf{2}$ & 4.86 & $2 \mathrm{H}$ & $-\mathrm{CH}_{2}$ \\
\hline $\mathbf{3}$ & 2.50 & $2 \mathrm{H}$ & $-\mathrm{CH}$ \\
\hline
\end{tabular}

Structure of 2-(4-(3-(p-tolyl)acryloyl)phenoxy) -N, N-diphenylacetamide (RKCT8)<smiles>Cc1ccc(/C=C/C(=O)c2ccc(OCC(=O)N(c3ccccc3)c3ccccc3)cc2)cc1</smiles>

Physical parameters

$\begin{array}{ll}\text { Practical yield } & 0.98 \mathrm{~g} \\ \text { Percentage yield } & 82.35 \% \\ \text { Melting range } & 129-132^{\circ} \mathrm{C} \\ \text { Rf value } & 0.84 \\ \text { Mobile phase } & n \text { - hexane: Ethyl acetate (1:1) } \\ \text { Molecular formula } & \mathrm{C}_{30} \mathrm{H}_{25} \mathrm{NO}_{3}\end{array}$

Graph 15. IR spectrum of 2-(4-(3-(p-tolyl) acryloyl) phenoxy) )-N, N-diphenylacetamide (RKCT8)

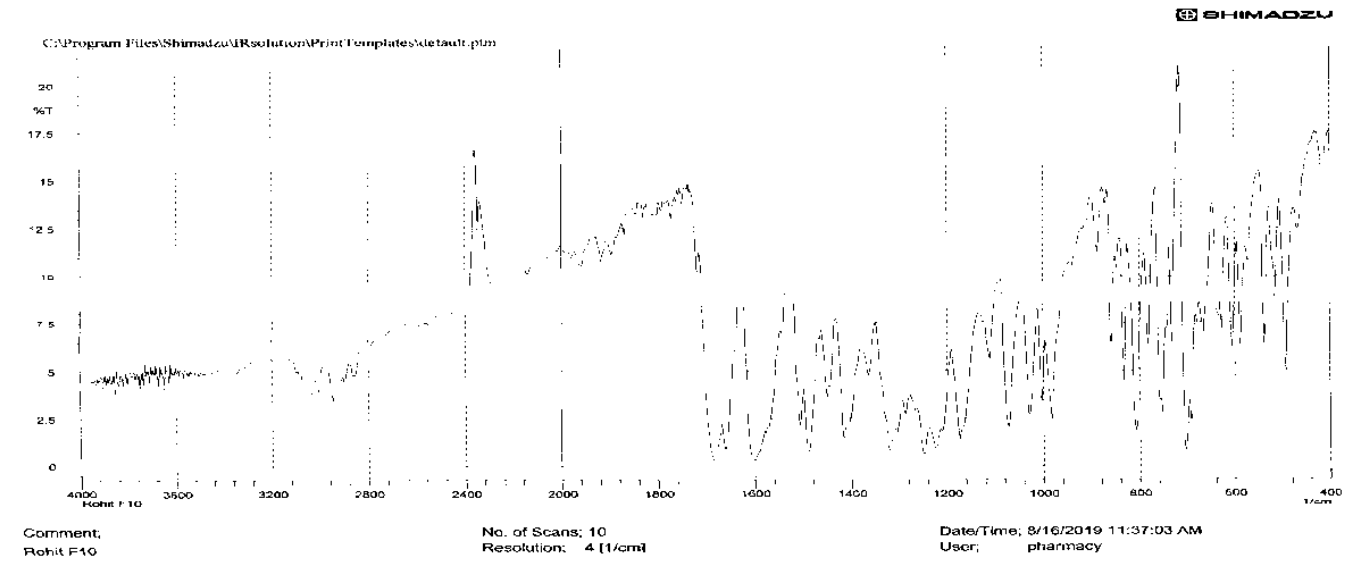


Table 16. IR spectrum data of 2-(4-(3-(p-tolyl) acryloyl) phenoxy)-N,N-diphenylacetamide (RKCT8)

\begin{tabular}{|c|c|c|}
\hline S.No. & Functional Group Assignment & $\mathbf{v}\left(\mathbf{c m}^{-1}\right)$ \\
\hline $\mathbf{1}$ & C-H str. Ar. & 3040 \\
\hline $\mathbf{2}$ & C-H str. Ali & 2950 \\
\hline $\mathbf{3}$ & C=O str. & 1720 \\
\hline $\mathbf{4}$ & C=C str. Ar. & 1660 \\
\hline $\mathbf{5}$ & C-N str. & 1220 \\
\hline $\mathbf{6}$ & C-O-C str. & 1110 \\
\hline
\end{tabular}

Graph 16. NMR spectrum of 2-(4-(3-(p-tolyl) acryloyl) phenoxy)-N, N-diphenylacetamide (RKCT8)

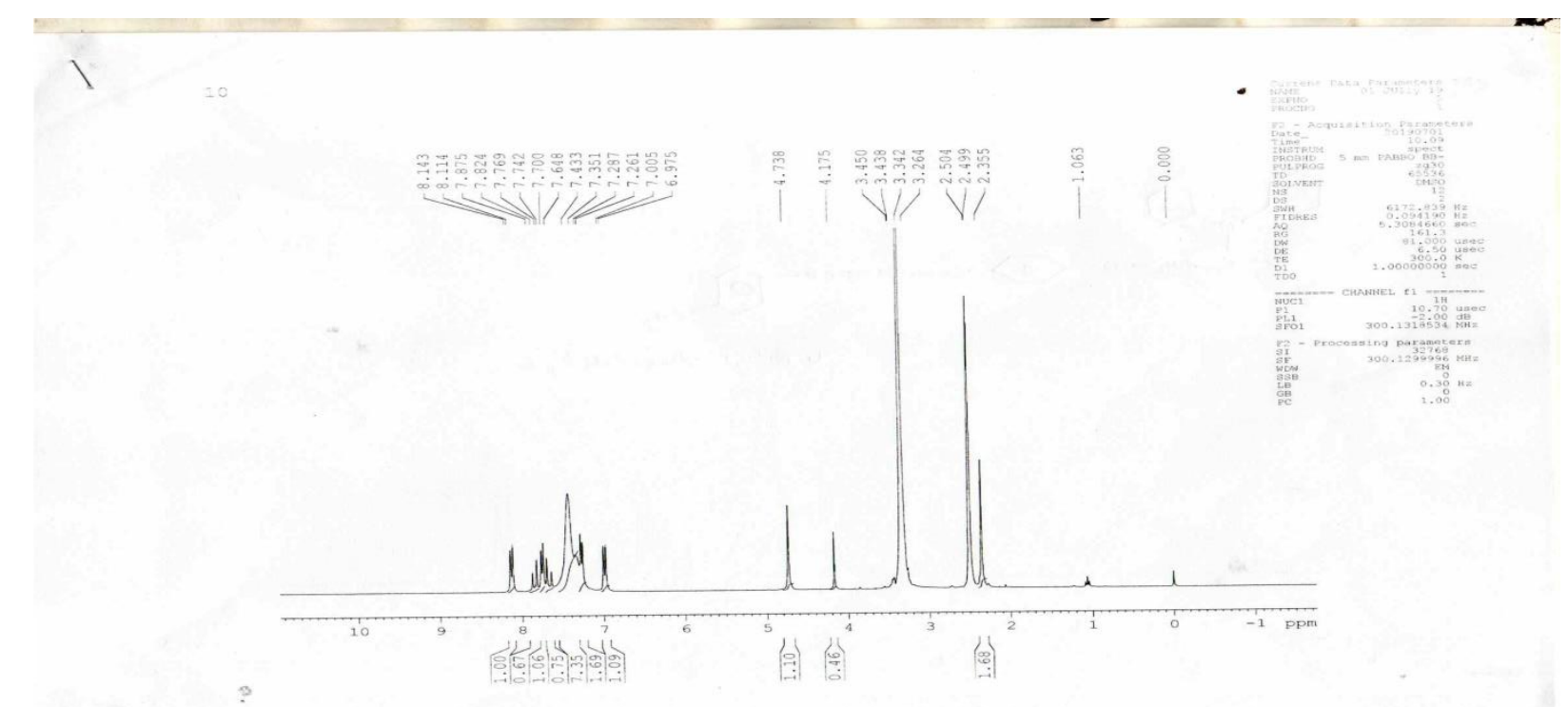

Table 17. NMR spectrum data of 2-(4-(3-(p-tolyl) acryloyl) phenoxy)-N,N-diphenylacetamide (RKCT8)

\begin{tabular}{|c|c|c|c|}
\hline S.No & Chemical shift( $)(\mathbf{p p m}$ & No. of Protons & Inferences \\
\hline $\mathbf{1}$ & $6.97-8.14$ & $18 \mathrm{H}-\mathrm{H}$ \\
\hline $\mathbf{2}$ & 4.73 & $2 \mathrm{H}$ & $-\mathrm{CH}_{2}$ \\
\hline $\mathbf{3}$ & 3.4 & $2 \mathrm{H}$ & $-\mathrm{CH}$ \\
\hline $\mathbf{4}$ & 2.50 & $3 \mathrm{H}$ & $-\mathrm{CH}_{3}$ \\
\hline
\end{tabular}

Structure of 2-(4-(3-(3,4-dimethoxyphenyl)acryloyl)phenoxy)-N,N-diphenyl acetamide (RKCT9)<smiles>COc1ccc(C=CC(=O)c2ccc(OCC(=O)N(c3ccccc3)c3ccccc3)cc2)cc1OC</smiles>

Physical parameters:

$\begin{array}{ll}\text { Practical yield } & 1.12 \mathrm{~g} \\ \text { Percentage yield } & 78.87 \% \\ \text { Melting range } & 128-131^{\circ} \mathrm{C} \\ \text { Rf value } & 0.46 \\ \text { Mobile phase } & \text { n- hexane: Ethyl acetate (1:1) } \\ \text { Molecular formula } & \mathrm{C}_{31} \mathrm{H}_{27} \mathrm{NO}_{5}\end{array}$


Graph 17. NMR spectrum data of 2-(4-(3-(p-tolyl) acryloyl) phenoxy)-N, N-diphenylacetamide (RKCT8)

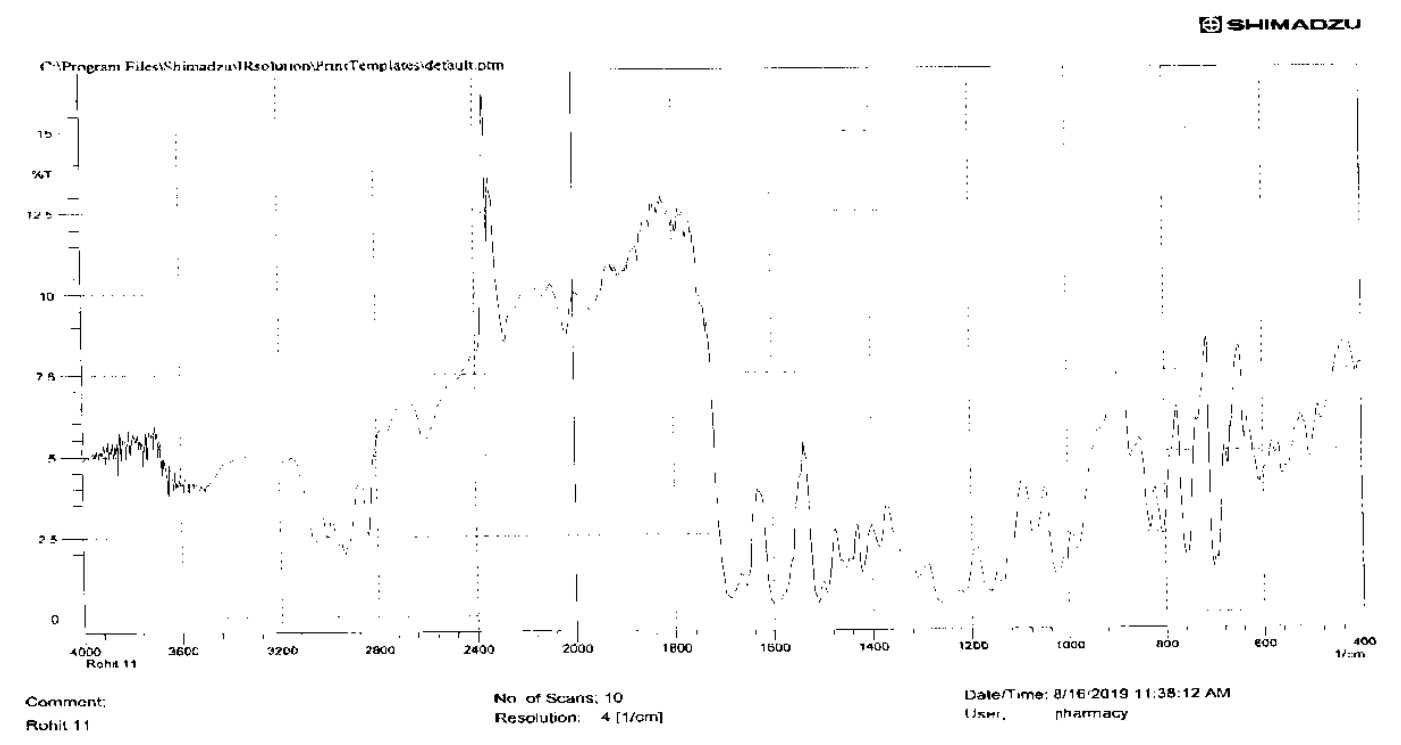

Table 18. IR spectrum data of 2-(4-(3-(3,4-dimethoxyphenyl) acryloyl) phenoxy)-N,N-diphenylacetamide (RKCT9)

\begin{tabular}{|c|c|c|}
\hline S.No. & Functional Group Assignment & $\mathbf{v ~ ( \mathbf { c m } ^ { - 1 } )}$ \\
\hline $\mathbf{1}$ & C-H str. Ar. & 3060 \\
\hline $\mathbf{2}$ & C-H str. Ali & 3000 \\
\hline $\mathbf{3}$ & C=O str. & 1720 \\
\hline $\mathbf{4}$ & C=C str. Ar. & 1660 \\
\hline $\mathbf{5}$ & C-N str. & 1230 \\
\hline $\mathbf{6}$ & C-O-C str. & 1140 \\
\hline
\end{tabular}

Graph 18. NMR spectrum of 2-(4-(3-(3,4-dimethoxyphenyl)acryloyl) phenoxy)-N,N-diphenylacetamide (RKCT9)

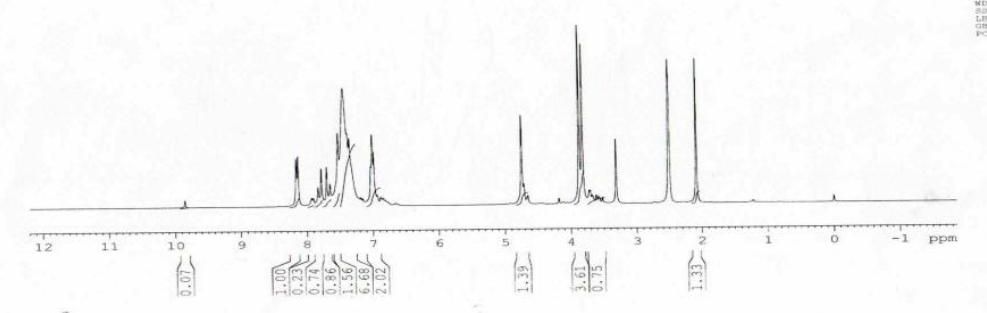

Table 19. NMR spectrum data of 2-(4-(3-(3,4-dimethoxyphenyl) acryloyl) phenoxy) -N,N-diphenylacetamide (RKCT9)

\begin{tabular}{|c|c|c|c|}
\hline S.No & Chemical shift( $)(\mathbf{p p m}$ & No. of Protons & Inferences \\
\hline $\mathbf{1}$ & $6.65-9.85$ & $17 \mathrm{H}-\mathrm{H}$ \\
\hline $\mathbf{2}$ & 4.74 & $2 \mathrm{H}$ & $-\mathrm{CH}_{2}$ \\
\hline $\mathbf{3}$ & 3.87 & $6 \mathrm{H}$ & $-\mathrm{OCH}_{3}$ \\
\hline $\mathbf{4}$ & 2.50 & $2 \mathrm{H}$ & $-\mathrm{CH}$ \\
\hline
\end{tabular}


Structure of 2-(4-(3-(2-chlorophenyl) acryloyl) phenoxy)-N, N-diphenyl acetamide (RKCT10)<smiles>O=C(C=Cc1ccccc1Cl)c1ccc(OCC(=O)n2c3ccccc3c3ccccc32)cc1</smiles>

Physical parameters
Practical yield
$1.014 \mathrm{~g}$
Percentage yield
$78.60 \%$
Melting range
$136-139^{\circ} \mathrm{C}$
$\mathrm{R}_{\mathrm{f}}$ value
0.80
Mobile phase
n- hexane: Ethyl acetate (1:1)
Molecular formula
$\mathrm{C}_{29} \mathrm{H}_{22} \mathrm{ClNO}_{3}$

Graph 19. IR spectrum of 2-(4-(3-(2-chlorophenyl)acryloyl)phenoxy)-N,N- diphenylacetamide (RKCT10)

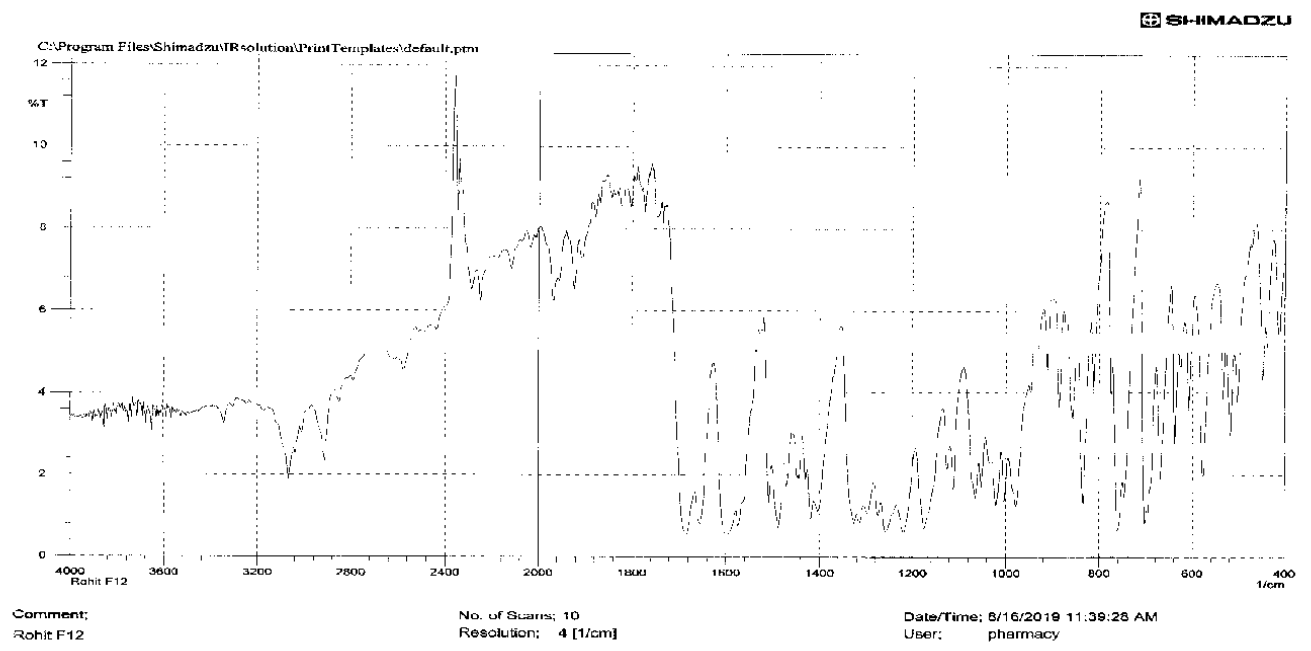

Table 20. IR spectrum data of 2-(4-(3-(2-chlorophenyl) acryloyl) phenoxy) -N, N- diphenylacetamide (RKCT10)

\begin{tabular}{|c|c|c|}
\hline S.No. & Functional Group Assignment & $\mathbf{v}\left(\mathbf{c m}^{-\mathbf{1}}\right)$ \\
\hline $\mathbf{1}$ & C-H str. Ar. & 3065 \\
\hline $\mathbf{2}$ & C-H str. Ali & 2910 \\
\hline $\mathbf{3}$ & C=O str. & 1725 \\
\hline $\mathbf{4}$ & C=C str. Ar. & 1680 \\
\hline $\mathbf{5}$ & C-N str. & 1220 \\
\hline $\mathbf{6}$ & C-O-C str. & 1110 \\
\hline $\mathbf{7}$ & C-Cl str. & 840 \\
\hline
\end{tabular}


Graph 20. NMR spectrum of 2-(4-(3-(2-chlorophenyl) acryloyl) phenoxy) -N, N- diphenylacetamide (RKCT10)

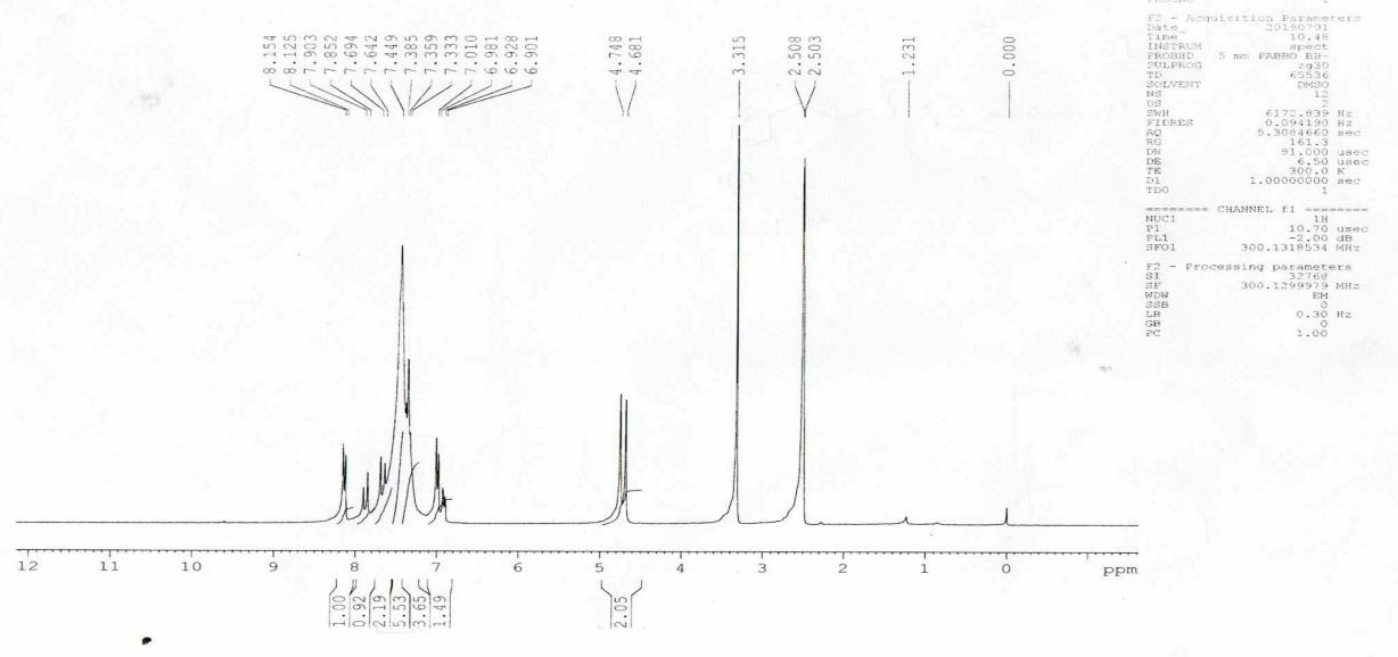

Table 21. NMR spectrum data of 2-(4-(3-(2-chlorophenyl) acryloyl) phenoxy) -N, N-diphenylacetamide (RKCT10)

\begin{tabular}{|c|c|c|c|}
\hline S.No & Chemical shift( $\boldsymbol{\delta})(\mathbf{p p m}$ & No. of Protons & Inferences \\
\hline $\mathbf{1}$ & $7.00-8.21$ & $18 \mathrm{H}-\mathrm{H}$ \\
\hline $\mathbf{2}$ & 4.75 & $2 \mathrm{H}$ & $-\mathrm{CH}_{2}$ \\
\hline $\mathbf{4}$ & 2.51 & $2 \mathrm{H}$ & $-\mathrm{CH}$ \\
\hline
\end{tabular}

\section{Pharmacological Evaluation}

Table 22. The Antimicrobial Activity of target compounds (RKCT1-10)

\begin{tabular}{|l|l|l|l|}
\hline Cpd. Code & $\begin{array}{l}\text { Zone of Inhibition } \\
\text { (in mm) against } \\
\text { B. Subtilis }\end{array}$ & $\begin{array}{l}\text { Zone of Inhibition } \\
\text { (in mm) against } \\
\text { E. Coli }\end{array}$ & $\begin{array}{l}\text { Zone of Inhibition } \\
\text { (in mm) against } \\
\text { C. Albicans }\end{array}$ \\
\hline RKCT1 & 20 & 20 & 16 \\
\hline RKCT2 & 20 & 20 & 22 \\
\hline RKCT3 & 20 & 20 & 16 \\
\hline RKCT4 & 12 & 14 & 12 \\
\hline RKCT5 & 16 & 12 & 16 \\
\hline RKCT6 & 14 & 16 & 14 \\
\hline RKCT7 & 16 & 14 & 12 \\
\hline RKCT8 & 14 & 16 & 14 \\
\hline RKCT9 & 14 & 16 & 16 \\
\hline RKCT10 & 14 & 24 & - \\
\hline Ampicillin & 26 & - & 24 \\
\hline Clotrimazole & - & 16 & \\
\hline
\end{tabular}

The target compound (chalcones) were designed and synthesized and screened to antimicrobial activity. The target compounds (RKCT1-10) were synthesized by reaction of chloroacetylchloride with diphenylamine to afford 2chloro- $\mathrm{N}, \mathrm{N}$-diphenylacetamide which further by reaction with substituted Chalcones. All the reactions were monitored by TLC. All the target compounds were purified by recrystallization and characterized by spectroscopic methods. The target compounds were tested for activity against B. Subtilis, E.Coli and C. albicans. The results of antimicrobial activity are shown in table 22 . 
The chalcones having the lipophilic 4-chloro group (RKCT2) showed the greatest antimicrobial activity (zone of inhibition $20 \& 22 \mathrm{~mm}$ against. B. subtilis, E. Coli, C. Albicans respectively.

\section{CONCLUSION}

The target compound having 4-bromogroup (RKCT3) showed the greatest antibacterial activity (zone of inhibition $20 \mathrm{~mm}$ against B. Subtilis \& E. Coli, respectively, whereas Chalcone without substitution (RKCT1) also showed mild antibacterial activity.

It suggests further researchers to go through anti-microbial evaluations against a more varieties of bacteria and fungi. It may a promising compound for the cure of numerous ailments caused by same micro-organisms.

\section{REFERENCES}

1. Wermuth C.G., Ganellin C.R., Lindberg P., Mitcher L.A., Glossary of terms used in medicinal chemistry, IUPAC Recommendations, 1998; 385-389.
2. Dingermann T, Sterinhilber D, Folker F., Methods and Principals in Medicinal Chemistry, 2000; 1-2.

3. Beale J.M., Block Wilson J.H., Text Book of Medicinal and Pharmaceutical chemistry. Lippincott Williams and welkin publication, 2011; 12:1-2.

4. Sahoo Mohan Biswa., Rajeswari Mullangi., Jnyanaranjan Panda., Sahoo Binayani.,A., Green expedient synthesis of pyrimidine derivatives via chalcones and evaluation of their anthelmintic activity. Indian Journal of Pharmaceutical Education and Research, 2017; 51(4S):701-705.

5. Elfi Susanti V.H., Widiastuti Agustina., Eko Setyowati., A green synthesis of chalcones as an antioxidant and anticancer. International Conference on Chemistry and Material Science (IC2MS), 2017; 299.

6. Yerragunta Vishwanadham., Kumaraswamy T., Suman, Anusha, Patil Prathima D.V., Samhitha T., A review on chalcones and its importance, Pharm Tutor Magazine. 2017; 1(2):54-59.

7. Prashar Hatish., Chawla Anshul., Sharma Anil Kumar., Kharb Rajeev., Chalcone as a versatile moiety for diverse pharmacological activities, IJPSR, 2012;; 3(7):1913-1927.

8. Kumar Sushil., Kumar Ajay., Verma Shweta., Mishra Arun K., Synthesis of some new Schiff bases of Pharmaceutical Interest, Ann Adv Chem., 2017; 1:53-56. 